\title{
Characteristics and Development of Shape-Memory Alloy Heat Engine*
}

\author{
Hisaaki TOBUSHI $^{* *}$, Kousuke DATE ${ }^{* *}$ and Kouji MIYAMOTO ${ }^{* *}$ \\ **Aichi Institute of Technology, \\ 1247 Yachigusa, Yakusa-cho, Toyota, 470-0392, Japan \\ E-mail: tobushi@aitech.ac.jp
}

\begin{abstract}
Since a solid-state heat engine using a shape memory alloy (SMA) works at the temperature difference of several ten degrees, the development of the SMA-heat engine to use the low-temperature thermal energy around $373 \mathrm{~K}$ is greatly expected from a view-point of global warming prevention. The working principle of the SMA-heat engine is discussed based on the recovery stress of the SMA. The output power characteristics of a tilt-disk offset crank SMA-heat engine and the basic working properties of a solar-powered car using an SMA-heat engine are investigated. The subjects for the development of the SMA-heat engine are also discussed.
\end{abstract}

Key words: Shape Memory Alloy, Heat Engine, Recovery Stress, Output Power, Tilt-Disk Offset Crank Engine, Solar-Powered Car

\section{Introduction}

It is necessary to construct the system to use the low-temperature thermal energy around $373 \mathrm{~K}$ from a view-point of global warming prevention. Only a small part of these low-grade thermal energies has been used effectively. A solid-state heat engine using a shape memory alloy (SMA) ${ }^{(1)-(3)}$ works at the temperature difference of several ten degrees ${ }^{(4)(5)}$. Since the SMA heat engine is compact and harmless clean engine, the development of the engine is greatly expected. In the SMA, the martensitic transformation (MT) appears by the small temperature difference, and the recovery stress of $400 \sim 600 \mathrm{MPa}$ appears due to the reverse transformation (RT). The recovery stress of the SMA depends on strain, temperature and the heating-cooling condition. In order to develop and design the SMA heat engine, it is necessary to clarify the thermomechanical properties of the SMA and the dependence of output power of the engine on these factors.

In the present paper, the working principle of the SMA-heat engine, the recovery stress for the driving force of the engine and the development of the engine are discussed. The output power characteristics of a tilt-disk offset crank heat engine using the SMA and the basic working properties of a solar-powered car using a simple-pulley SMA heat engine are investigated. The subject for the development of the SMA-heat engine will be also discussed.

\section{Working Principle of SMA-Heat Engine}

The working principle of an SMA-heat engine is shown in Fig. 1. A weight of $w_{2}$ is added to a lengthened SMA-helical spring at low temperature (d). If the spring is heated, it contracts with a displacement of $h(\mathrm{a})$. In the heating process, the effective work of $w_{2} h$ can be obtained (b). After removing the weight of $w_{2}$ followed by cooling, the SMA spring

${ }^{\star}$ Received 16 Nov., 2009 (No. e4-2) [DOI: 10.1299/jmmp.4.1094]

Copyright $@ 2010$ by JSME 
lengthens (c). If these heating and cooling processes (a)-(d) are repeated, we can obtain the work of $w_{2} h$ at each cycle. In order to perform these thermal cycles smoothly, various types of the SMA-heat engines have been proposed.

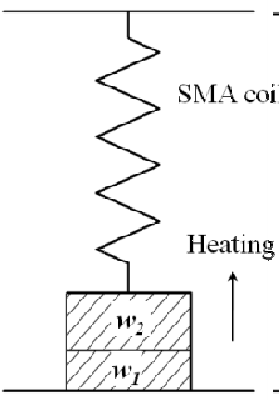

(a)

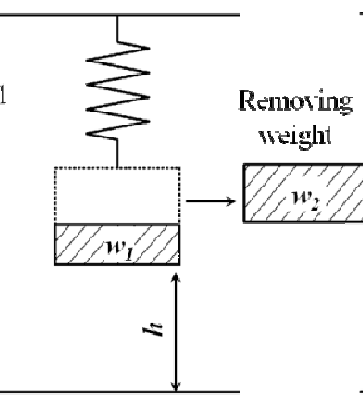

(b)

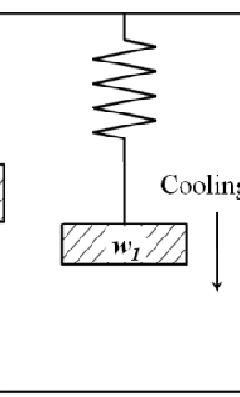

(3)

Fig.1 Working principle of SMA-heat engine

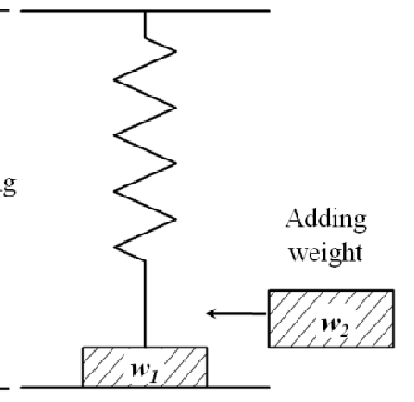

(d)

\section{Recovery Stress for Driving Force in SMA-Heat Engine}

The driving force in the SMA-heat engine is obtained from the recovery stress which appears in the SMA element. In order to understand the characteristics of the recovery stress, the stress-strain diagram and the stress-temperature phase diagram which show the generation of the recovery stress after pre-loading are shown in Fig. 2 . In the figure, $M_{s}, M_{f}$, $A_{s}$ and $A_{f}$ denote the start and finish temperatures of the marfensitic transformation and the reverse transformation, respectively. At first, the pre-load is applied to the point $\mathrm{A}$ and is removed at the temperature $T_{o}$ below $A_{s}$. After removing the pre-load, the residual strain $\varepsilon \mathrm{r}$ appears at the point B. By keeping $\varepsilon_{\mathrm{r}}$ constant, if the SMA elements are heated to the point $\mathrm{C}$, the recovery stress increases due to the reverse transformation. The recovery stress depends on the hysteresis of the thermomechanical loading. That is, the recovery stress depends on the pre-loading conditions of stress $\sigma_{0}$, strain $\varepsilon_{0}$, volume fraction of the martensitic phase $z_{0}$ and the heating and cooling conditions. Therefore, it is important to understand the dependence of the recovery stress on these thermomechanical conditions in order to develop the SMA-heat engine.

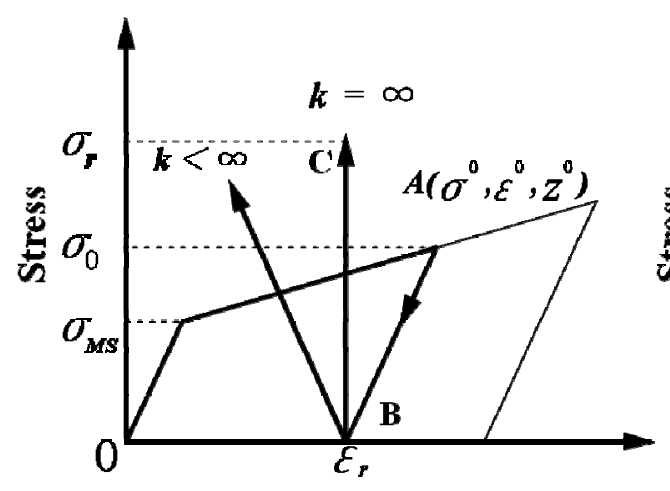

Strain

(a) Stress-strain diagram

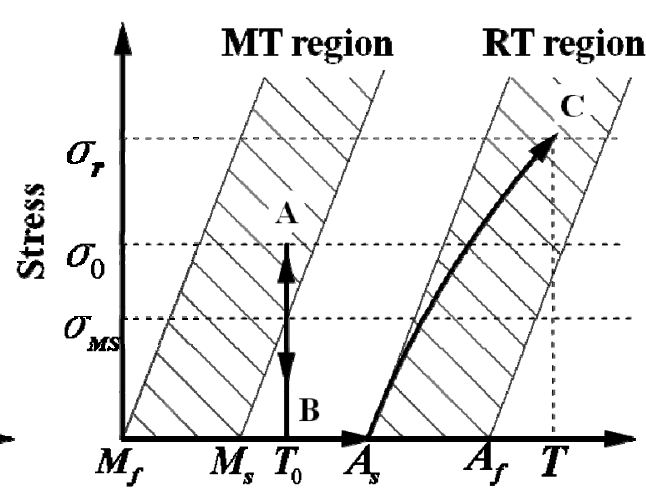

Temperature

(b) Stress-temperature phase diagram Fig.2 Stress-strain diagram and stress-temperature phase diagram showing the generation of the recovery stress

\section{Development of SMA-Heat Engine}

Various kinds of the SMA-heat engine have been developed till now ${ }^{(4)-(19)}$. The type and output power characteristics of the proposed SMA-heat engines are summarized in Table 1.

An offset-crank SMA heat engine was first proposed by Banks ${ }^{(4)}$. The bending deformations of the SMA wires were used in this engine. Another offset-crank SMA heat engine using the SMA helical springs was proposed by Ginell et al. ${ }^{(5)}$. The basic structure and working principle of this engine is shown in Fig. 3. The centers of the large and small disks are eccentric by a distance of $e_{x}$. The points on the circumferences of two disks are 
connected by the SMA helical springs. The recovery force $F_{h}$ induced in the helical spring in hot water is stronger than that $F_{a}$ in air. The disks rotate due to the tangential component of the contractile recovery force $F_{h t}$.

A tilt-disk SMA heat engine was proposed by Nishikawa et al. ${ }^{(7)}$. The basic structure and working principle of this engine is shown in Fig. 4. Two disks are inclined by an angle of $\beta$. The points on the circumferences of two disks are connected by the SMA coils. The heating region is shifted by a heating-phase angle $\phi$ for the position BB' of the maximum length of the SMA coil. The disks rotate due to the stronger tangential component of the contractile recovery force in hot water $F_{h t}$.

If the number of SMA elements increases, the driving force due to the recovery stress increases ${ }^{(18)}$ and therefore we can obtain the higher output power.

Table 1 Type and output power of various SMA-heat engines

\begin{tabular}{|l|l|c|c|c|l|}
\hline \multirow{2}{*}{ Type of engine } & \multicolumn{3}{c|}{ Driving element of SMA } & $\begin{array}{c}\text { Maximum } \\
\text { output }\end{array}$ & Reference \\
\cline { 2 - 5 } & Shape & $\begin{array}{c}\text { Number of } \\
\text { elements }\end{array}$ & $\begin{array}{c}\text { Type of } \\
\text { deformation }\end{array}$ & power [W] & \\
\hline Offset crank & Wire & 20 & Bending & 0.23 & Banks (4) \\
Offset crank & Helical spring & -- & Tension & 20 & Ginell (5) \\
Offset crank & Helical spring & 6 & Tension & 1 & Tobushi (18) \\
Simple pulley & Wire & 5 & Bending & 0.28 & Tobushi (18) \\
Simple pulley & Belt & 1 & Bending & 1.2 & Sato (14) \\
Twin crank & Helical spring & 6 & Tension & 1.7 & Iwanaga (16) \\
Tilt disk & Helical spring & -- & Tension & 6.2 & Nishikawa (7) \\
Tilt-disk offset crank & Wire & -- & Elongation & 305 & Nishkawa (8) \\
Reciprocating & Helical spring & 12 & Tension & 0.6 & Tobushi (19) \\
Reciprocating & Wire & 2 & Elongation & 1.8 & Sakuma (12, 13) \\
Turbine & Wire & 1 & Elongation & 0.15 & Kaneko (15) \\
Turbine & Belt & 1 & Bending & 0.6 & Tanaka (11) \\
\hline
\end{tabular}

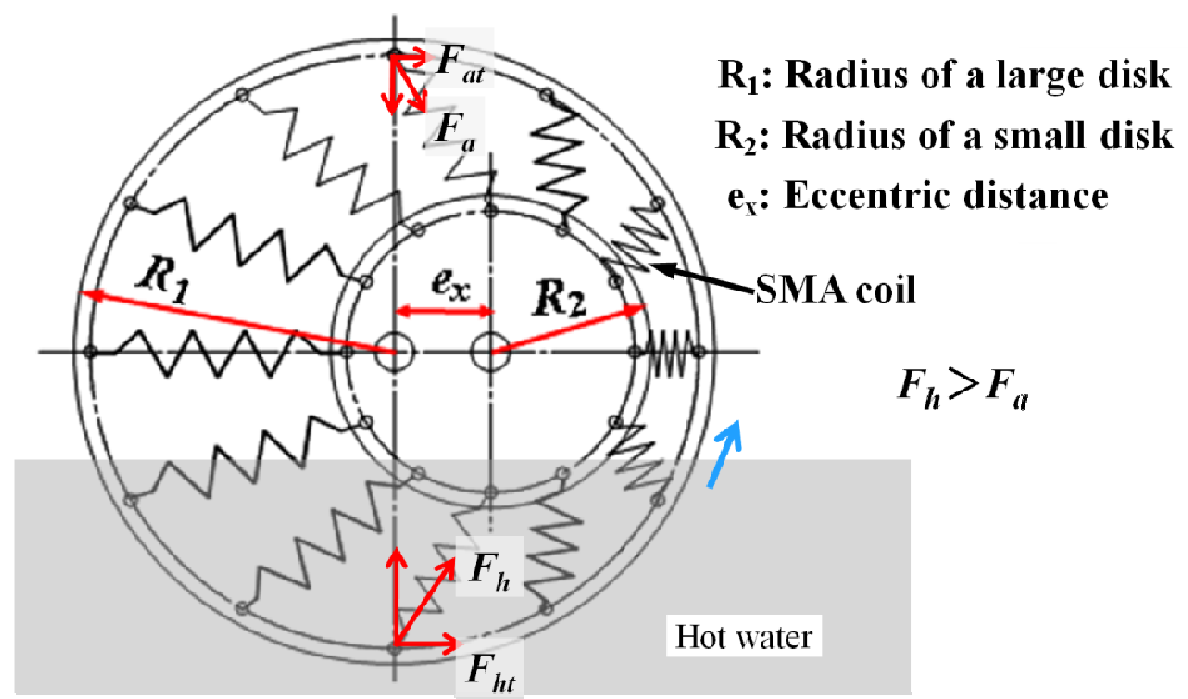

Fig. 3 Basic structure and working principle of an offset-crank SMA heat engine 


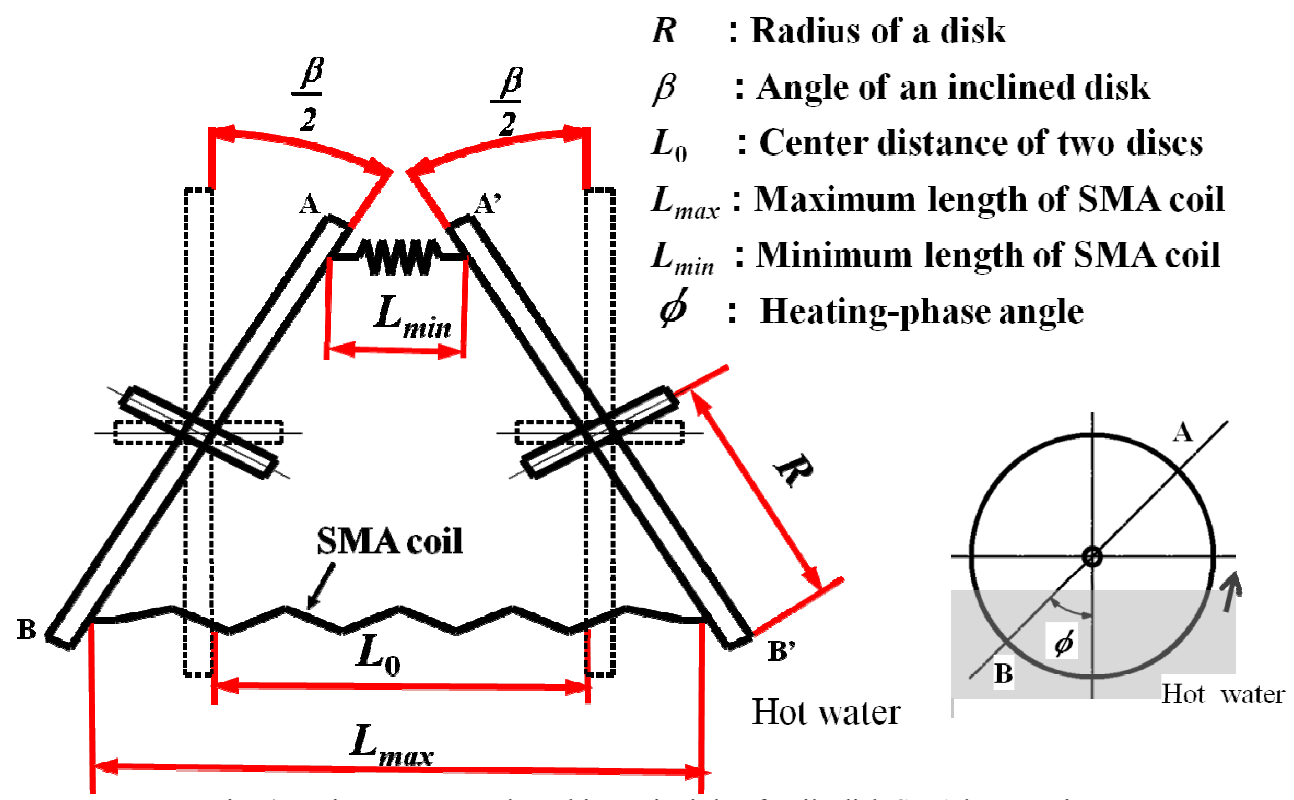

Fig. 4 Basic structure and working principle of a tilt-disk SMA heat engine

\section{Tilt-Disk Offset Crank SMA Heat Engine}

A tilt-disk offset crank SMA heat engine was proposed by Tobushi et al. ${ }^{(19)}$.

The photographs of a tilt-disk offset crank SMA heat engine are shown in Fig. 5. The basic mechanism of this engine was constructed by combining a tilt-disk SMA heat engine and an offset-crank SMA heat engine. The SMA coils connect the circumferences of two tilt disks. The contractile recovery force of the SMA coil is the driving force of the engine. The recovery force of the SMA coil in hot water is stronger than that in air. The difference in the contractile force of the SMA coils between in the hot reservoir and in the cold reservoir is the key value of the engine. The disks rotate due to the tangential component of the contractile force. The experiment was carried out by the following condition: a diameter of the SMA wire of $0.7 \mathrm{~mm}$, a mean spring diameter of the SMA coil of $8.7 \mathrm{~mm}, R_{1}=100 \mathrm{~mm}$, $R_{2}=75 \mathrm{~mm}, e_{x}=5 \mathrm{~mm}, L_{0}=80 \mathrm{~mm}, \beta=20^{\circ}, \phi=0^{\circ}$ and a distance of $68 \mathrm{~mm}$ between a large-disk shaft and the surface of hot water. The relationship between output power and rotational speed for various numbers of SMA helical springs $N_{s}$ in the tilt-disk offset crank SMA engine obtained by the experiment is shown in Fig. 6. As seen in Fig. 6, the output power increases in proportion to the number of SMA helical springs $N_{s}$. The maximum output power is $0.17 \mathrm{~W}$ at a rotational speed of $60 \mathrm{rpm}$ for a number of SMA coils of 24 . The characteristics of the output power of the engine depend on various factors. The output power is affected by the shape of SMA coil, the center distance of two disks, the radii of tilt disks, the inclined angle, the heating phase angle, the temperatures of the hot and cold reservoirs. 

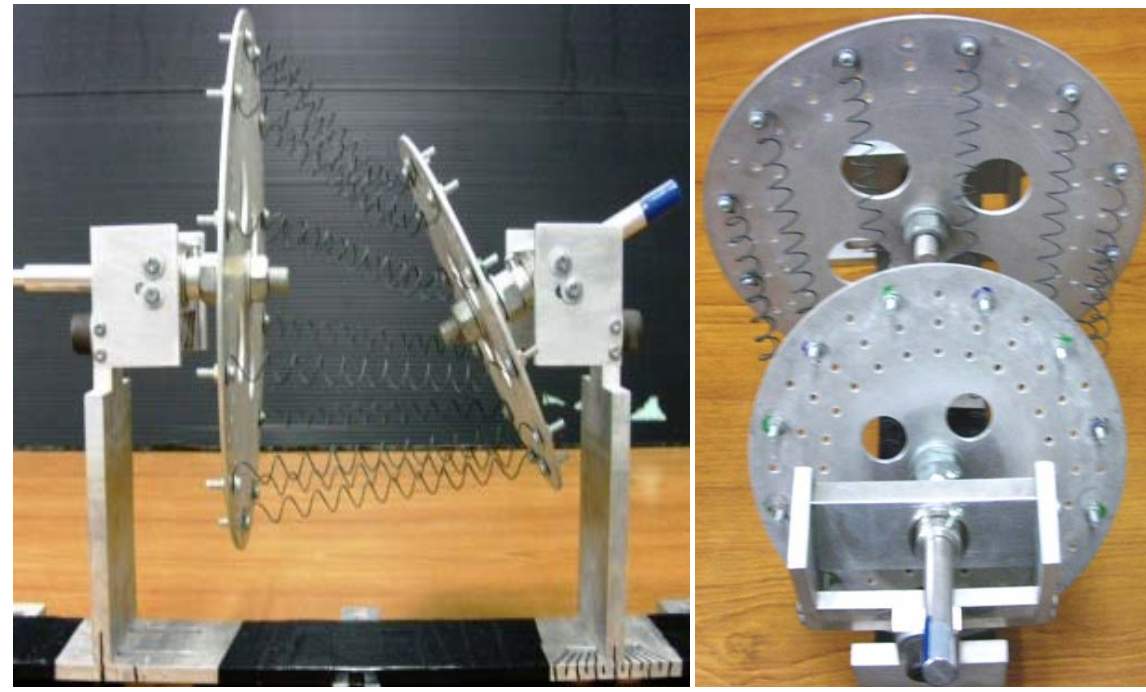

Fig. 5 Photographs of a tilt-disk offset crank SMA heat engine

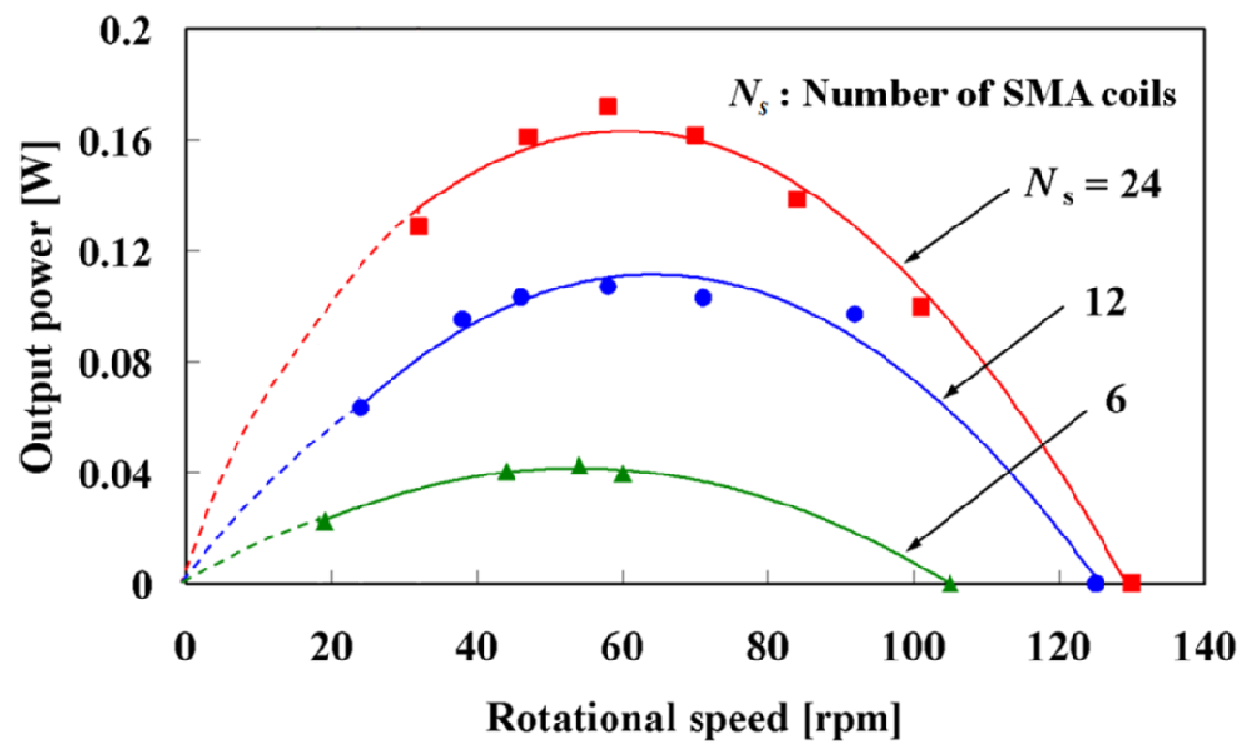

Fig. 6 Relationship between output power and rotational speed for various numbers of SMA coils $N_{s}$ in the tilt-disk offset crank SMA heat engine

\section{Solar-Powered Car Driven by Simple-Pulley SMA Heat Engine}

A photograph of a solar-powered car driven by a simple-pulley SMA heat engine is shown in Fig. 7. The basic structure of a simple-pulley SMA heat engine driven by the sun light using a Fresnel lens is shown in Fig. 8. In the simple-pulley SMA heat engine, two pulleys are connected by the SMA belt. The flat plane of the SMA belt was shape-memorized. The loop of the SMA belt was made by the welding. The sunlight is focused by a Fresnel lens. If the SMA belt in the left hand part on a small pulley is heated by the sunlight, the SMA belt moves to the left based on the recovery force. The pulley rotates counterclockwise by the friction between the SMA belt and the pulley and therefore the car shown in Fig. 7 moves to the left. If the SMA belt in the right hand part on a small pulley is heated, the SMA belt moves to the right and the pulley rotates clockwise, resulting in the movement of the car to the right. Therefore, we can control the moving direction of the car by changing the heating part of the SMA belt on a small pulley. The relationship between velocity and air temperature in the solar-powered car obtained for a distance between two pulleys of $115 \mathrm{~mm}$, a prop angle $\theta$ of $40^{\circ}$ and a distance between the Fresnel lens and the small pulley of $60 \mathrm{~mm}$ and $70 \mathrm{~mm}$ is shown in Fig. 9. A focal distance and a diameter of the Fresnel lens were $152 \mathrm{~mm}$ and $76 \mathrm{~mm}$, respectively. Velocity increases in proportion to the air temperature since the recovery stress in the SMA belt increases in 
proportion to temperature. The maximum average speed of the car obtained by the experiment was $1.49 \mathrm{~m} / \mathrm{min}$.

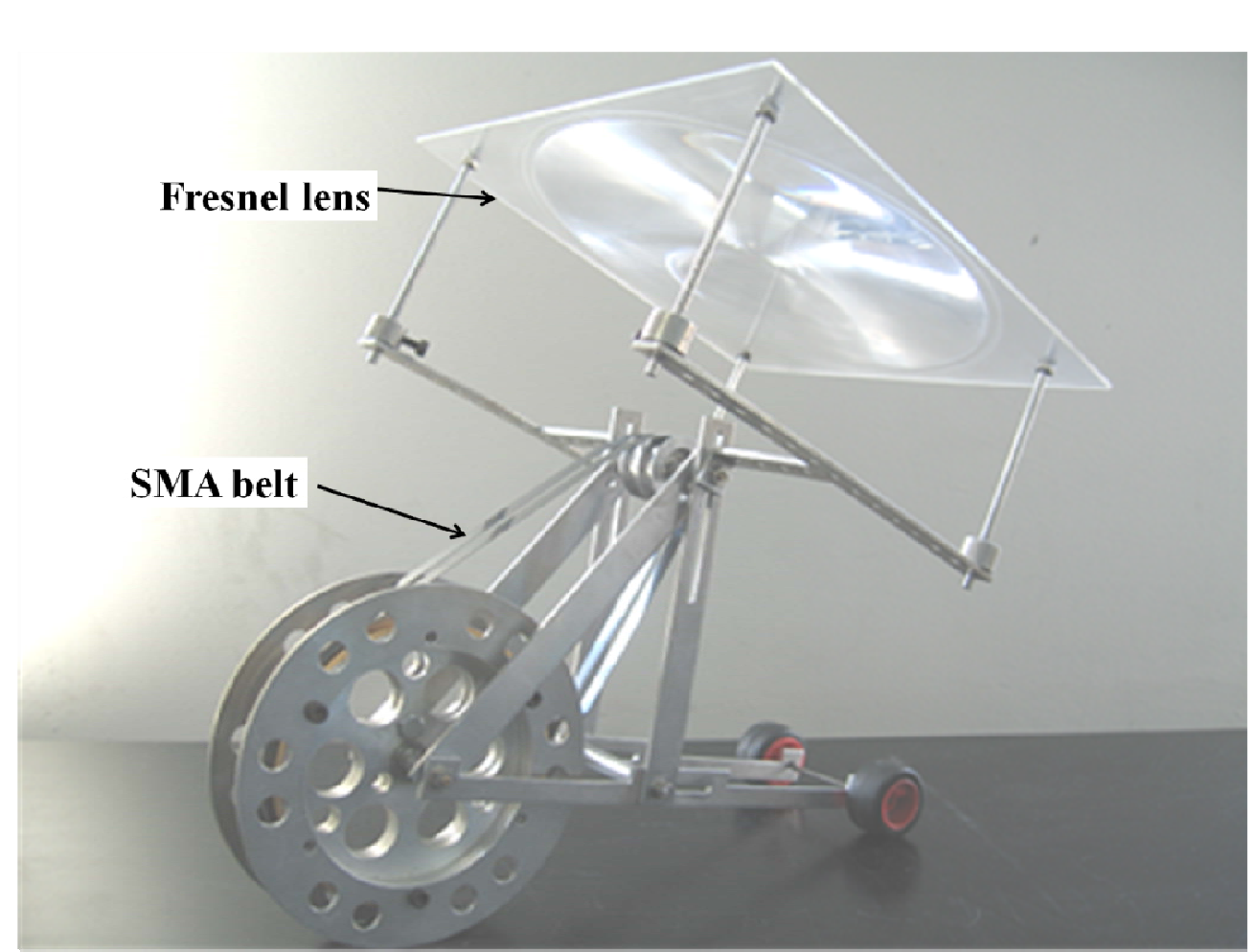

Fig. 7 Photograph of a solar-powered car driven by a simple pulley SMA heat engine

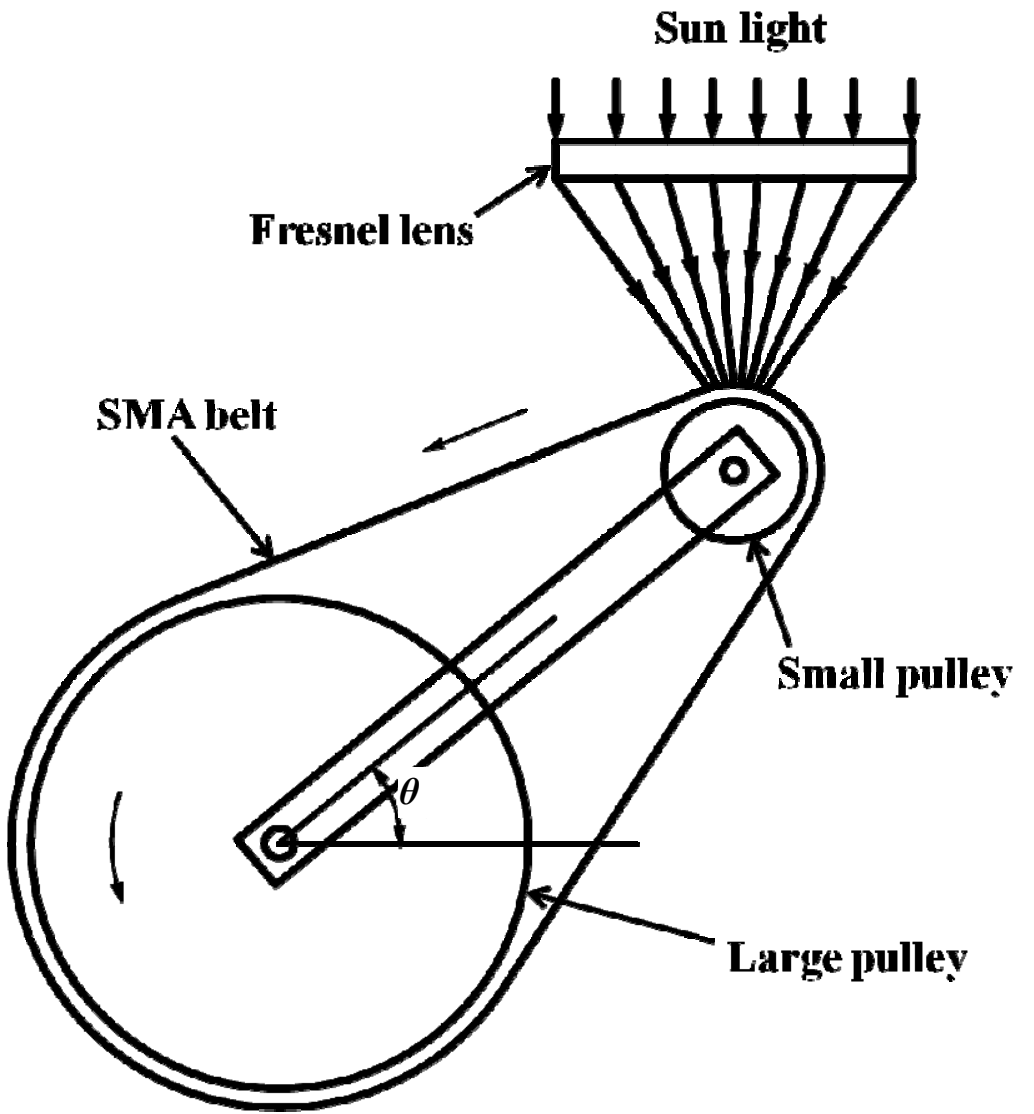

Fig. 8 Basic structure of a simple-pulley SMA heat engine driven by sun light using Fresnel lens 


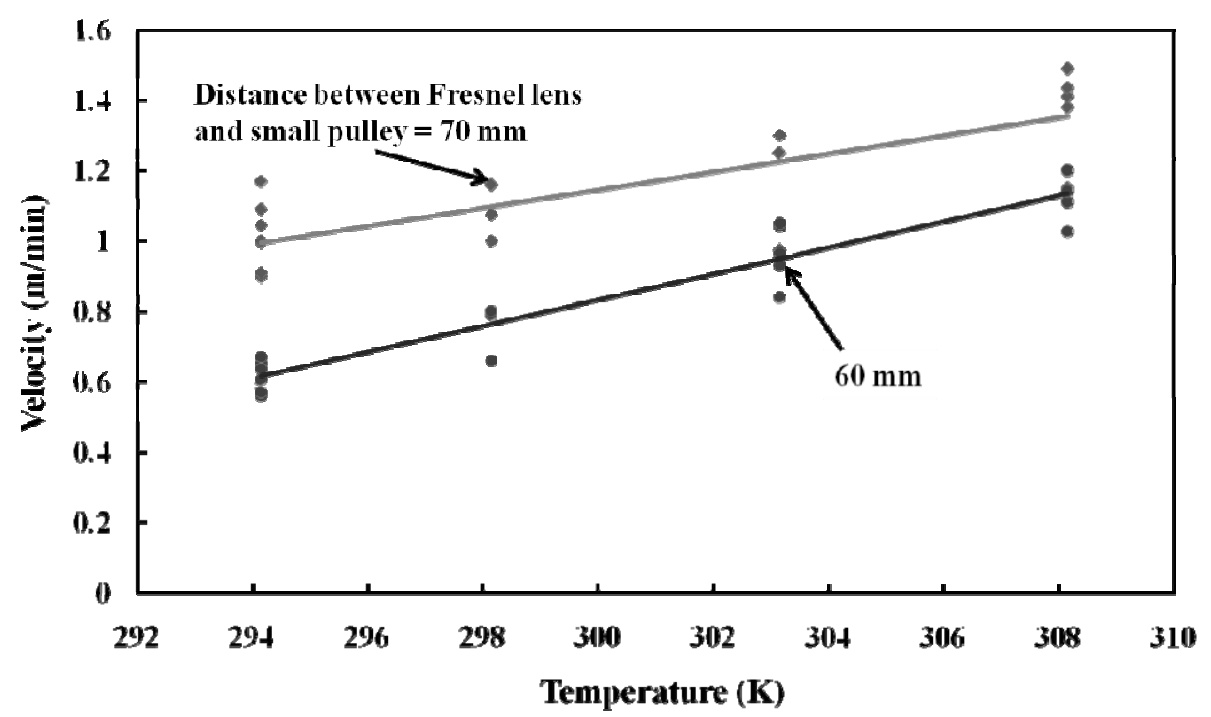

Fig. 9 Relationship between velocity and air temperature in the solar-powered car

\section{Subjects for Development of SMA-Heat Engine}

The development of the SMA-heat engine is highly expected as discussed in the previous sections. In order to develop the SMA-heat engine in the practical application, there are various subjects to be solved. The main subjects for the development of the SMA heat engine can be summarized as follows.

(1) Construction of the system to use the unused low-temperature thermal energy

Most of the thermal energies with the temperature below $373 \mathrm{~K}$ of the wasted heat from factories, the geothermal energy, the hot water from the hot springs and the solar energy are not used. The system to use these thermal energies in the SMA-heat engine is necessary to be constructed.

(2) Development of the effective energy conversion system using the SMA

Although the deflection of the SMA spring is very large, the recovery force is small. The recovery force of SMA wire in tension or the SMA tube in torsion can be large. The effective mechanism of the SMA-heat engine to use the large recovery force which appears in the SMA element is necessary to be developed.

(3) Improvement of degradation of the mechanical properties of the SMA

The martensitic transformation stress decreases in the early cycles of repetition. Although the recovery stress increases with an increase in strain and temperature, the decrease in the transformation stress is also large. The martensitic transformation temperature varies under the thermal and mechanical cycling. The material with slight change in the transformation stress, recovery stress and transformation temperature under the thermal and mechanical cycling is necessary to be developed.

(4) Improvement of the fatigue life of the SMA

Although the corrosion resistance of TiNi SMA is very high, the corrosion fatigue may occur under the repetition of large strain. The material with long fatigue life is necessary to be developed.

(5) Improvement of efficiency for energy conversion

The SMA-heat engine uses the low-grade thermal energy, and therefore the efficiency for conversion of thermal to mechanical energy is basically low. However, the efficiency of the engine for energy conversion is still necessary to be increased.

\section{Conclusions}

The output power characteristics of the tilt-disk offset crank SMA heat engine and the basic working properties of the solar-powered car using the simple-pulley SMA heat engine were clarified. The subject for the development of the SMA heat engine was discussed. The 
development of the SMA-heat engine is highly expected from a view-point of global warming prevention.

\section{Acknowledgements}

The experimental work of this study was carried out with the assistance of the students of Aichi Institute of Technology, to whom the authors with to express their gratitude. The authors also wish to express their gratefulness to the Scientific Research (C) (General) of Grant-in-Aid for Scientific Research by the Japan Society for the Promotion of Science for financial support.

\section{References}

(1) Funakubo, H., ed., Shape Memory Alloys, (1987), pp. 1-60, Gordon and Breach Science Pub.

(2) Duerig, T. W., Melton, K. N., Stockel, D. and Wayman, C. M., eds., Engineering Aspects of Shape Memory Alloys, (1990), pp. 1-35, Butterworth-Heinemann.

(3) Otsuka, K. and Wayman, C. M., eds., Shape Memory Materials, (1998), pp. 1-49, Cambridge University Press.

(4) Banks, R., Nitinol Heat Engines, Shape Memory Effects in Alloys, edited by J. Perkins, pp. 537-545, (1975), Plenum Press.

(5) Ginell, W.S., McNichols, Jr. J. L. and Cory, J. S., Nitinol Heat Engines for Low-Grade Thermal Energy Conversion, Mech. Eng., Vol. 101, No. 5, (1979), pp. 28-33.

(6) Goldstein, D. M. and McNamara, L. J., eds., Proc. NITINOL Heat Engine Conf., NSWC-MP-79-441, (1978), pp. 11.1-12.16.

(7) Nishikawa, M. and Watanabe, K., Working Characteristics of Tilt-Disk Heat Engine and Driving Element Using SMA, Proc. Autumn Sym. Japan Inst. Metal, pp. 122-123, (1983), (in Japanese).

(8) Nishikawa, M., Kodera, M., Okata, I., Yamauchi, K. and Watanabe, K., Large Scale Tilt Plate Heat Engine Using SMA, Proc. Int. Conf. Martensitic Transformations, (1986), pp. 1041-1046.

(9) Honma, T., Netsu, N., Nisida, M., Matumoto, M., Shugo, Y. and Ohkawa, A., Performance of Nitinol Heat Engine, Bull. Res. Inst. Mineral Dressing and Metallurgy, Tohoku University, Vol. 37, No. 2 (1981), pp. 213-222 (in Japanese).

(10) Tanaka, H., Kanda, M., Sugimoto, S., Mouri, M., Okuda, T. and Tanaka, T., Heat Engine Using TiNi Shape Memory Alloy, Proc. Autumn Sym. Japan Inst. Metal, (1983), pp.120-121 (in Japanese).

(11) Tanaka, M., Future Engine, J. JSME, Vol. 93, No. 855 (1990), pp. 119-122 (in Japanese).

(12) Sakuma, T., Iwata, U. and Arai, M., Output Power Characteristics of Reciprocating Heat Engine Using Shape Memory Alloy, JSME Int. J., Ser. B, Vol. 40, No. 4 (1997), pp. 599-606.

(13) Sakuma, T. and Iwata, U., Working Characteristics of a Reciprocating-Type Heat Engine Using Shape Memory Alloys, JSME Int. J., Ser. B, Vol. 41, No. 2 (1998), pp. 344-350.

(14) Sato, Y., Kobayashi, M., Kobayashi, Y. and Suzuki, M., Study on the Output Power Characteristics of the Shape Memory Alloy Engine (3rd Report), Trans. JSME, Ser. B, Vol. 74, No. 741 (2008), pp. 1154-1160, (in Japanese).

(15) Kaneko, K. and Enomoto, K., Development of Reciprocating Heat Engine Using Shape Memory Alloy - Ratchet Type Drive System with One-Way Clutch - , Proc. Int. Conf. Shape Memory and Superelastic Tech., (2007), pp.359-368.

(16) Iwanaga, H., Tobushi, H. and Ito, H., Basic Research on Output Power Characteristics of a Shape Memory Alloy heat Engine (Twin Crank Heat Engine), JSME Int. J., Ser. I, Vol. 31, No. 3 (1988), pp. 634-637.

(17) Tobushi, H. and Cahoon, J. R., Mechanical Analysis of a Solar-Powered Solid State 
Engine, Trans. CSME, Vol. 9, No. 3 (1985), pp. 137-141.

(18) Tobushi, H., Kimura, K., Iwanaga, H. and Cahoon, J. R., Basic Research on Shape Memory Alloy Heat Engine (Output Power Characteristics and Problems in Development), JSME Int. J., Ser. I, Vol. 33, No. 2 (1990), pp. 263-268.

(19) Tobushi, H., Okumura, K., Shimeno, Y. and Takata, K., Output Power Characteristics of Tilt-Disk Offset Crank Heat Engine Using Shape Memory Alloy, Trans. Mater. Res. Soc. Japan., Vol. 26, No.1 (2001), pp. 171-174. 